case records were examined to identify any correlates with the results. Vitamin D was classified as deficient, insufficient or adequate with total 25 -hydroxy vitamin $\mathrm{D}$ blood levels of $<12.5$, 12.5-50 and $>50 \mathrm{nmols} / \mathrm{l}$ respectively.

Results 143 patients had a least one vitamin D level measured. Of these 7 (5\%) had vitamin D deficiency, 83 (58\%) insufficient levels and $53(37 \%)$ had adequate levels. Comparing patients who had levels tested in the winter months with those tested in the summer, they were more likely to show deficient or insufficient levels than adequate levels $(44 / 90(49 \%)$ vs $6 / 53(11 \%)$ p < 0.0001). All patients who showed gross deficiency were black or Asian but there wasn't a correlation between ethnicity and insufficient/deficient levels. Three (42\%) of the patients with deficient levels had a raised serum alkaline phosphotase and/or a low serum phosphate.

Conclusions High rates of vitamin D deficiency and insufficiency were found in this cohort, only part of which is explained by doing the test in the winter months. Some evidence of metabolic effects of deficiency on bone was found

\section{P11 HIV TEST UPTAKE IN THE GU CLINIC: JUNIORS HOT ON THE HEELS OF THE CONSULTANTS}

doi:10.1136/sextrans-2012-050601c.11

0 Isabel, ${ }^{*}$ M D Portman, R Giuntini, CMW Stewart, J D Wilson. Leeds General Infirmary

Background Data from the Health Protection Agency shows that $25 \%$ of people living with HIV in the UK are unaware of their diagnosis. This has serious health implications for them and others.

The National Strategy for Sexual Health and HIV set a target of $60 \%$ testing uptake by $2007.69 \%$ of STI attendees at GUM clinics in England in 2010 were tested for HIV. Regional data from the Health Protection Unit shows a 70\% uptake of HIV testing in women attending our clinic. Recent data from the UK and Australia has documented variable HIV testing rates among clinicians with a trend towards more junior doctors being more likely to offer a test. Objectives To identify HIV testing rates according to grade of clinician.

Methods Women attending our service as new or rebook patients between March 2009 and January 2010 were seen by clinicians representing eight different grades of staff. The women's response to the offer of an HIV test was recorded. These data were analysed according to the grade of the staff member.

Results 3973 women were seen by 42 different clinicians. 2982 accepted an HIV test (P1A); 980 declined a test (P1B) and 11 deferred testing (P1C) (see abstract P11 table 1).

Conclusions There are many perceived barriers to HIV testing and it is often quoted that testing rates are lowest among non-specialists.
However, there is little published data on the impact of the individual clinician on HIV testing. Encouragingly, our data has shown that more junior staff, having trained in an environment where HIV is increasingly recognised as a treatable condition, are confident to offer HIV testing and do so as effectively as consultants. We should learn from them with respect to promoting HIV testing in our clinics and not underestimate the value of ongoing training and support in this important area.

\section{P12 HIV TESTING: ARE WE DOING ENOUGH? A STAFF AWARENESS SURVEY IN EAST MIDLANDS}

doi:10.1136/sextrans-2012-050601c.12

J Dhar, ${ }^{*}$ F Nyatsanza. University Hospitals of Leicester, Leicester, UK

Background The overall HIV prevalence in East Midland is low and since 2000 most of the new cases in our region continue to be diagnosed in the same three Primary Care Trusts, peaking in the 35-39-year-old adults in 2009/2010. HIV uptake rates vary from $69 \%$ to $80 \%$ and high coverage remains a possibility as demonstrated by $96 \%$ antenatal uptake rates.

Objective To collect information from hospital and community based staff about HIV testing, to develop effective regional strategies.

Methods A 10 min online Questionnaire was completed by staff members via Survey Monkey this included gender, age, time since qualification, experience of HIV test use, training issues etc.

Results 1067 responses have been analysed, $>75 \%$ of respondents being female, representing a wide range of specialties including general practice. $21 \%, 28 \%, 28 \%, 22 \%$ are aged between $20-30$ years, $30-40$ years, $40-50$ years and $>50$ years respectively. $25.5 \%, 21 \%, 25 \%, 29 \%$ of the respondents were qualified $<5$ years, 5-10 years, $10-20$ years, more than 20 years respectively. $46.8 \%$ had no prior experience of offering an HIV test. $39.9 \%$ felt they had the necessary skills a similar proportion $39.5 \%$ felt they lacked them. $21.8 \%$ of the respondents would have concerns offering a test. While the majority $81.6 \%$ agreed with NICE guidance on expanded testing $57.7 \%$ would require further training, $50.2 \%$ saying they would be unable to answer patients questions on HIV testing. 85.1\% agreed that HIV updates need to be incorporated in induction provided to health care professionals with $45.9 \%$ stating that current methods were not adequate.

Conclusions The survey highlights that while health care professionals are aware of the need to have a HIV test nearly half of them have never offered one and a large proportion have identified anxieties around consultation. Inadequate training was cited as a major factor for not considering or offering a test.

Abstract P11 Table 1 HIV testing rates by different health care professionals

\begin{tabular}{|c|c|c|c|c|c|c|c|c|c|}
\hline & Band 5 nurses & Band 6 nurses & FY1 & ST2 & GP & SAS & Reg & Cons & Total \\
\hline No of staff & 6 & 7 & 6 & 4 & 2 & 2 & 9 & 6 & 42 \\
\hline No of consultations & 169 & 442 & 140 & 207 & 252 & 837 & 996 & 930 & 3973 \\
\hline P1A & 122 & 325 & 112 & 171 & 196 & 572 & 753 & 731 & 2982 \\
\hline P1B & 47 & 115 & 28 & 36 & 52 & 265 & 239 & 198 & 980 \\
\hline P1C & 0 & 2 & 0 & 0 & 4 & 0 & 4 & 1 & 11 \\
\hline $\begin{array}{l}\% \text { Patients who } \\
\text { decline HIV test }\end{array}$ & 27.8 & 26.0 & 20.0 & 17.4 & 20.6 & 30.6 & 24.0 & 21.3 & 24.7 \\
\hline $\begin{array}{l}\text { OR }(95 \% \mathrm{CI}) \text { patient } \\
\text { having an HIV test } \\
\text { compared to } \\
\text { other grades }\end{array}$ & $\begin{array}{l}1.18 \\
(0.84 \text { to } 1.67)\end{array}$ & $\begin{array}{l}1.08 \\
(0.86 \text { to } 1.36)\end{array}$ & $\begin{array}{l}0.76 \\
(0.49 \text { to } 1.15)\end{array}$ & $\begin{array}{l}0.63 \\
(0.44 \text { to } 0.19)\end{array}$ & $\begin{array}{l}0.78 \\
(0.57 \text { to } 1.07)\end{array}$ & $\begin{array}{l}1.57 \\
(1.33 \text { to } 1.86)\end{array}$ & $\begin{array}{l}0.95 \\
(0.81 \text { to } 1.13)\end{array}$ & $\begin{array}{l}0.78 \\
(0.66 \text { to } 0.93)\end{array}$ & \\
\hline p Value & 0.38 & 0.52 & 0.23 & 0.016 & 0.14 & $<0.0001$ & 0.60 & 0.007 & \\
\hline
\end{tabular}

